\title{
Induced Abortion in N igeria: Findings from Focus Group Discussion
}

\author{
Boniface $A \quad 0$ ye $A$ deniran ${ }^{1,5}$, I saac $F$ A dewole $e^{2,5}, A$ ugustine $V \quad U$ moh $^{3}, \mathrm{~N}$ gozi I were and $A$ bidoye \\ $G$ badegesin 4
}

\begin{abstract}
ABST RACT
A bortion is carried out daily in $\mathrm{N}$ igeria despite the restrictive abortion law. This study was carried out to obtain information on societal attitude to the issues of family planning, unwanted pregnancy, abortion, adoption of children and laws relating to them. Focus group discussions were held in south-western $\mathrm{N}$ igeria among 11 subgroups. Participants felt that there was high prevalence of unwanted pregnancy and abortion particularly among youths. They had high level awareness of contraceptives and ascribed its low use to negative side effects, high cost and provider bias. Christians favoured planning of pregnancies while the Muslims did not. Majority of the respondents had negative perception of induced abortion. Some of them supported abortion if the education of the young girl would be disrupted, if paternity of pregnancy is in dispute, or if it would save the family from shame. Participants supported the enactment of laws that would make adoption of unwanted children easier.
\end{abstract} (A fr J R eprod H ealth 2005; 9[1]: 133-141)

RÉ SUMÉ

L'avortement provoqué au N igéria: Découvertes à partir d'une discussion à groupe cible. M algre la loi restrictive contre l'avortement, les femmes se font avorter chaque jour au N igéria. Cette étude a été menée afin d'obtenir des renseignements sur l'attitude de la société par rapport aux questions de la planification familiale, la grossesse non-désirée, l'avortement, l'adoption des enfants et les lois qui les concernent. Les discussions à groupe cible ont eu lieu au sud-ouest du N igéria parmi onze sous-groupes. Les participants avaient estimé qu'il y a une haute fréquence de grossesse non-désirée et de l'avortement surtout chez la jeunesse. Ils avaient un niveau élevé de la connaissance des contraceptifs et ils ont attribué son faible utilisation aux effets secondaires, le coût élevéet le préjugé des fournisseurs. Les chrétiens ont favoriséla planification de grossesse alors que les musulmans nel'ont pas favorisé. La majorité des répondants avaient une mauvaise perception de l'avortement si l'éducation de la jeune fille serait dérangée, si la paternité de la grossesse est contestable ou bien s'il sauverait la famille de honte. Les participants ont favorise la promulgation des lois qui rendra plus facile l'adoption des enfants non-désérés.(R ev A fr SantéR eprod 2005; 9[1]: 133-141)

KEY Wo RDS: C ontraception, adolescents, awareness, N igeria

${ }^{1} D$ epartment of 0 bstetrics \& $G$ ynaecology, $C$ ollege of $M$ ediane, U niversity of $L$ agos (CM U L ), L agos, N igeria. ${ }^{2} D$ epartment of $O$ bstetrics \& G ynaecology, C ollege of M edicine, U niversity of I badan, I badan, $N$ igeria. ${ }^{3} \mathrm{D}$ epartment of $\mathrm{O}$ bstetrics \& $G$ ynaecology, U niversity of $U$ yo Teaching $H$ ospital, $U$ yo, N igeria. ${ }^{4} \mathrm{D}$ epartment of $O$ bstetrics \& G ynaecology, A yinke H ouse, L agos State U niversity T eaching H ospital (L A SU TH ), Ikeja, N igeria. ${ }^{5} \mathrm{C}$ oordinator, The Campaign A gainst U nwanted P regnancy (T he CA U P), L agos, N igeria.

Correspondence: B oniface A . O yeA deniran, $D$ epartment of $O$ bstetrics \& $G$ ynaecology, $C$ ollege of $M$ ediane, $U$ niversity of L agos (C M U L ), L agos, N igeria. E -mail: oye@ beta.link serve.com, bonifaceoye@ yahoo.com 


\section{Introduction}

Unsafe abortion is a major reproductive health problem in $\mathrm{N}$ igeria and indeed in many developing countries with a significant contribution to maternal morbidity and mortality. ${ }^{1-4}$ It has been reported to account for $22.5-40 \%$ of maternal mortality incidence in $\mathrm{N}$ igeria, with similar figures from other countries. ${ }^{2,3,5}$ An estimated 610,000 abortions are being performed in N igeria annually, ${ }^{6}$ despite the restrictive abortion laws in the country, where a penalty of 7-14 years is prescribed for the abortion seeker and provider respectively. ${ }^{6,7}$ Poor contraceptive prevalence rates have further contributed to the worsening situation of unwanted pregnancy, a major precursor of abortion. ${ }^{7-9}$ Contraceptives are considered a first line of defence against unwanted pregnancy. ${ }^{7}$ It has been estimated that by the age of 45 years, $95 \%$ of women would have had an induced abortion, ${ }^{10}$ which suggests that most women would at some point in life have experienced unwanted pregnancy. Despite the increasing mortality associated with unsafe abortion, the resultant reproductive tract infection and consequent infertility, many women are not deterred.

Some researchers have suggested that power imbalance between men and women at both societal and personal levels is the cause of the prevailing unwanted pregnancy and consequent unsafe abortion. ${ }^{11}$ Studies have been conducted to elucidate and understand the factors that underlie this practice. This study was undertaken to provide qualitative information on induced abortion. It was carried out to specifically understand the attitudes of different population sub-groups towards induced abortion, to reveal their perception with respect to family planning, unwanted pregnancies, induced abortion and unwanted children. It was also meant to examine the factors that lead to unwanted pregnancies and induced abortion, to evaluate the quality of existing abortion care services, to examine the factors influencing the use of the existing services, to examine the psychological reactions of women to unwanted pregnancies, induced abortion and unwanted children, and to provide a basis for formulating guidelines for information, education and communication (IEC) interventions with regard to unwanted pregnancies.

\section{$M$ aterials and M ethod}

Focus group discussion (FGD) is an important method of illuminating the explanatory variables that are associated with attitude and behaviour of human populations. ${ }^{12-16}$ It is also considered to be an important supplement in the process of data collection on the qualitative aspect of studies and has, therefore, increasingly gained credibility in social science research. FGD has various advantages, namely, it allows a wide range of view points within a short period, respondents can correct and invalidate each other's points and supplement each other's information on the issue being discussed. It also permits openness, which is always absent at the level of individual interviews. It was therefore used for this study.

E leven subgroups in the more urban Lagos State and the more rural E do State of N igeria were identified, and focus group sessions held for each subgroup. The 11 identified sub-groups were:

1. Single young women, 15-24 years, rural/ urban

2. Married young women, 15-24 years, rural/ urban

3. Married women, 25-49 years, rural/ urban

4. Single women, 25-49 years, urban

5. M arried women, $>50$ years, rural/ urban

6. Single men, 15-24 years, urban

7. Married men, $>25$ years, rural/ urban

8. Christian religious leaders, urban

9. Muslim religious leaders, urban

10. N urses/ community health workers ( $\mathrm{CHW}$ ), rural/ urban

11. Medical practitioners, urban

A frican Journal of Reproductive $H$ ealth V ol. $9 \mathrm{~N} 0.1$ A pril 2005 
$0 \mathrm{n}$ the whole, 17 sessions were held in each state and there were a maximum of 10 discussants in each FGD session. In order to formulate guidelines that would take cognizance of cultural differences, formative research was first conducted and a set of guidelines/ questions for the FGD were developed and field-tested. Facilitators who were fluent in both $\mathrm{E}$ nglish and the local language were chosen from different local government areas in the same zone and trained for the study. The discussions were taperecorded and notes taken by trained assistants. These were then transcribed immediately after the sessions in order to identify and agree on major opinions and attitudes expressed by the group. The study was conducted in 1997 in two states (L agos and $\mathrm{E} \mathrm{do}$ ) in south-western $\mathrm{N}$ igeria ( $H$ ealth Zone $B$ ).

This qualitative approach was chosen to complement the quantitative data, thus providing rich information on such relevant issues as family planning, unwanted pregnancy, abortion and adoption of children, and the laws relating to them. It would also provide the essential guidelines for design and implementation of the necessary interventions particularly in the areas where quality of life is considered important.

To aid the process of analysis and interpretation, nine crucial factors, which form the bedrock for the investigation, were generated from the objectives of the study. They are:

\footnotetext{
Prevalence of unwanted pregnancy, abortion or termination of pregnancy.

Characteristics of abortion seekers.

$\mathrm{N}$ otion of unwanted pregnancy.

Q uality of existing health care in relation to abortion.

A bortion methods used.

Factors influencing use of existing services. A bortion complications.

Psychological reaction of abortion care seekers.
}

A frican Journal of Reproductive $\mathrm{H}$ ealth $\mathrm{V}$ ol. $9 \mathrm{~N} 0.1 \mathrm{~A}$ pril 2005
A ttitude to unwanted pregnancy, induced abortion and unwanted children.

\section{Results and Discussion}

P revalence of U nwanted Pregnancy, A bortion or

Termination of Pregnancy

A nalysis of data from $L$ agos State revealed high prevalence of unwanted pregnancy, abortion or termination of pregnancy both in the rural and urban areas particularly among the youth (mostly school girls), married women and single women. $D$ ata from $E$ do State revealed that the incidence of unwanted pregnancy and abortion is less common in rural than urban area. It also revealed that unwanted pregnancy and abortion tend to be most rampant among the youths, particularly schoolgirls.

The data from both Lagos and E do States showed that a very significant percentage of focus group participants had good knowledge and awareness of family planning, the various methods of family planning, accessibility to family planning services and the side effects. The question, therefore, is why have good knowledge and awareness of family planning not led to a reduction in the prevalence of unwanted pregnancy and abortion? This could be due to the following reasons: (1) participants' emphasis (possibly based on direct or indirect experiences) on negative side effects such as overweight, cancer, hypertension, sterility, etc, tend to discourage the use of the family planning facilities, thus exposing many people, particularly theyoung ones, to the risk of unwanted pregnancy and subsequent abortion; (2) data from both states indicated that although family planning services existed they were not affordable to most people, which also discouraged the use of the facilities. These could in turn expose many people, particularly schoolgirls, low income single and married women to the risk of unwanted pregnancy and abortion. 


\section{A frican Journal of $\mathrm{R}$ eproductive $\mathrm{H}$ ealth}

The implication of the situation thus highlighted would be a need to counteract the erroneous belief in the side effects of family planning through public enlightenment. The obvious side effects should be highlighted and possible solutions emphasised. Furthermore, greater efforts should be made to ensure that family planning services are affordable to women of reproductive age. Above all, the natural methods of family planning such as periodic abstinence and breastfeeding should be emphasised as suggested by the study participants in rural $E$ do State. While promoting modern methods of family planning, there is a need to respect the wishes of those women who would rather use the natural methods. U se of a family planning method, whether modern or natural, is better than non-use of any, as it will help minimise the risk of unwanted pregnancy and abortion among women of reproductive age.

Results from adolescents in the urban areas of Lagos State indicated a preference for abortion as a method of contraception.

\section{Characteristics of A bortion Seek ers}

Based on the study results, abortion seekers from both L agos and E do States included all categories of women, ranging from the schoolgirls to married women who were over 40 years old and already had the number of children they desired. Included in this broad group were hawkers, apprentices, girls from rural areas, girls from broken homes, commercial sex workers, nursing mothers, etc.

When asked why these categories of women would want to terminate pregnancy, the respondents gave various reasons. First and foremost, they said that such pregnancies are considered unwanted or undesirable for one reason or the other. Such reasons include a disruption of education for the schoolgirl, old age, and reproductive health risk for women who are above 40 years old especially if they've al ready had several children. 0 ther reasons include economic; for commercial sex workers whose business would be adversely affected by pregnancy and childbirth, while for a married low income woman the problem would be how her family would cope with feeding and caring for an extra child.

However, if such pregnancies had been prevented through the use of family planning, there would have been no need to seek for abortion. While some women became exposed to the risk of unwanted pregnancy and subsequent termination because they avoided using family planning for fear of side effects or their inability to afford a method, others sought abortion as a result of family planning method failure. Furthermore, some women sought abortion because their husbands, who are the sole decisionmakers on such important matters, prevented them from using family planning.

There is therefore a need for public enlightenment on the problems of unplanned and unwanted pregnancies as well as the dangers inherent in unsafe abortion. Women should be encouraged to use family planning services by making necessary efforts to educate them on possible side effects and offering them various methods from which they can make their choices.

\section{Perception of U nwanted P regnancy}

A nalysis of data from both states revealed that pregnancy was welcome. Participants were of the view that pregnancy is a thing of joy to the woman and others around her. The M uslims felt that pregnancy is a gift from God and would not see the relevance of planning pregnancy since it is welcome any time it occurs. The Christians also saw pregnancy as a welcome occurrence but were not against planning pregnancy. It is pertinent to note that most communities in $\mathrm{N}$ igeria would welcome pregnancy and regard becoming pregnant as a happy occurrence. Hence, some of them regard unwanted pregnancy as a new and somewhat strange idea. Indeed, some of the M uslim participants stated that there is nothing like unwanted pregnancy.

A frican Journal of Reproductive $\mathrm{H}$ ealth $\mathrm{V}$ ol. $9 \mathrm{~N} 0.1 \mathrm{~A}$ pril 2005 
However, a significant percentage of the participants said some pregnancies could be regarded as unwanted. These include those involving schoolgirls, unmarried women, underaged and over-aged women, sick women and women who become pregnant too soon after having a baby.

There is a need for public enlightenment on the significance of planning pregnancy, emphasising the reality of unwanted pregnancy. Such enlightenment should clearly emphasise the prevention of unwanted pregnancy as a measure to significantly reduce the rate of abortion in the communities. Women should be encouraged to plan pregnancy with active involvement of their spouses.

\section{Q uality of Existing $\mathrm{H}$ ealth Services}

Respondents said that the available health services in the two states are of low quality. They claimed that despite the availability of many public hospitals, special efforts must be made to improve the capacity of health workers to deliver family planning services in order to achieve the desired results.

\section{A bortion M ethods $U$ sed}

Results from L agos and $E$ do States indicated that all groups, old and young, male and female, seemed to be familiar with the abortion methods generally used by women, particularly the traditional methods. Although participants from Lagos State showed greater awareness of the modern methods than those from E do State, both groups manifested deeper familiarity based on experience. For example, themodern methods mentioned by the Lagos State participants included dilatation and curettage ( $D$ and $C$ ), use of tablets, and injections. Traditional methods mentioned by both Lagos and E do State participants included use of lime, potash, ogogoro (a local alcoholic gin) or other hot drinks such as salt and vinegar, harp beer, brown codeine and fresh kolanut leaves. Some rural women above 50 years old in $\mathrm{E}$ do State mentioned the use of kolanut leaves from a plant whose root crosses a road. These are boiled and the broth given to the woman to drink in a calabash while sitting by the door. A nother method mentioned was the use of oz iza herbs prepared with native gin.

A substantial percentage of rural and urban women from both states had used the traditional methods personally or witnessed their use by others such as children, relations or wards at various times. That was probably how some of the women came to a conclusion that "traditional methods are only effective during the early stages of pregnancy". Many of the women had used modern methods after the traditional methods had failed, while others decided to deliver the babies.

It is common knowledge that our nation's health care system is still very much underdeveloped, and with the current economic situation in N igeria, the health care needs of majority of the populace cannot be met. Thus, many people still resort to traditional medicine as a way out of their health problem.

The contemplation of the provision of improved health care services with particular regard to abortion invariably involves concrete policy issues and actions such as a review of the existing abortion law. An eventual action plan, which should derive from this particular study, is the generation of necessary ideas to deal with such policy issues and actions.

Factors I nfluencing the $U$ se of $E$ xisting Services A nalysis of data from both L agos and $E$ do States revealed the availability of various modern and traditional family planning services. However, there is ample evidence that many women who need these services do not use them. The participants said although the services exist and are within their reach, e.g., in hospitals particularly the private hospitals, clinics, maternity homes, chemists and traditional homes, they are not 


\section{A frican Journal of R eproductive $H$ ealth}

affordable. The services were considered to be of poor quality, ineffective, often risky and could result in infertility or death. This makes a significant proportion of women to carry unwanted pregnancies and deliver unwanted babies. A substantial number of such babies end up being abandoned. Some of them die, while others end up in motherless babies' homes and foster homes where they may not receive adequate care and may not be properly brought up.

There is an urgent need to ensure that existing health services are utilised by women, but such issues can only be effectively tackled within the context of the problems of abortion, abortion law, and even adoption and adoption law. Thus, every effort should be made to deal with the policy and legal issues involved in order to enforce the rights and improve the quality of life of children and women that are involved.

\section{A bortion Complications}

Respondents from both states were familiar with the complications arising from unsafe abortion through personal experience or experience of relations, neighbours, friends and partners. They mentioned such complications as damage to the womb, infertility, delay in becoming pregnant, frequent miscarriages, haemorrhage and death. Indeed, there was high level awareness of abortion complications among the study participants. 0 ne therefore wonders why a substantial number of women still seek abortion under unsafe conditions in spite of the high level of awareness of its complications.

A bortion tended to be the last resort for a significant percentage of the women. There is enormous stigma associated with unwanted pregnancy especially for schoolgirls, single girls and married women especially those involved in extra-marital relationships and the economic strains involved in giving birth to a baby one is not prepared for. In cases of denied paternity there is a problem of the stigma of bearing a child who would be regarded as a bastard. Such a child would have to struggle through life with the problem of identity especially if he is a male. He would suffer neglect, discrimination, economic and emotional hardships. Women who terminate pregnancies are likely to have considered such issues before taking the action. They are also likely to have considered the option of giving birth to unwanted children and decided that the better choice was to go for abortion in spite of the complications that may arise. It therefore becomes the question of making a choice between the devil and the deep blue sea. This is not to say that every woman who resorts to abortion makes a choice based on such reasoning especially bearing in mind that some participants claimed that some adolescents regard abortion as a form of contraception. O ne tends to believe that these groups of women are likely to be in the minority.

A pertinent question that arose was whether, for the sake of the quality of life of women, making the abortion process safer could prevent the complications of abortion? This implies that skilled personnel should carry out the process, with the proper instruments and in hygienic environment. This pre-supposes that abortion is no longer considered a criminal act necessitating clandestine operations in hideouts and by unskilled personnel. This invariably calls for policy and legal reform, which points out to a need for advocacy to bring it about.

The alternative is to tackle those problems that predispose women to abortion. The low socio-economic situation of some women must be addressed. This tends to involve policy and legal issues. The state, through a concrete policy of intervention in the lives of children and mothers (particularly single mothers, through provision of employment and adequate care for the children) could encourage women to have their babies and give them up for adoption. H owever, from the data obtained, this suggestion may not be easy to achieve at present, since there

A frican Journal of Reproductive $H$ ealth V ol. $9 \mathrm{~N} 0.1$ A pril 2005 
is a significant indication that the $\mathrm{N}$ igerian society is not in support of adoption. A dopted children are more likely to be discriminated against than other children, and their rights could be abused. Fostering of children tends to receive a greater approval particularly among the $M$ uslim religious group. The authors however believe that with diligent public enlightenment on adoption there could be a breakthrough on the promulgation of a favourable adoption law. Married women above 50 years old in E do State said having an adoption law is good since it will reduce the rate of abortion.

\section{P sychological State of A bortion Seek ers}

Participants from both states had knowledge of the psychological state of women who procure abortion either from personal experience or the experiences of relations, neighbours, friends and partners. They mentioned feelings of relief (particularly on the part of school children who have gone through abortion successfully), guilt and trauma. Some women could become seriously upset if infertility occurs after the abortion. Such women could even become jealous of those who have children. Some women become scared and avoid having sex, while some married women hate their husbands and the unmarried ones keep away from boyfriends for a long time. Prostitutes were said to feel happy after successfully procuring abortion. They would be free again to go into full business. The psychological outcome of abortion could be traumatic when considered in line with the moral background of the $\mathrm{N}$ igerian society. The woman who has procured the abortion would certainly feel that she has committed a crime (not just against the law but against $\mathrm{G} \mathrm{od}$ ). This is probably why some women feel guilty and sad if they later become infertile. There is a tendency to feel that they are receiving the punishment of God for their offence. Such psychological state could hinder a woman from becoming pregnant, thus compounding her feeling

A frican Journal of Reproductive $\mathrm{H}$ ealth $\mathrm{V}$ ol. $9 \mathrm{~N} 0.1 \mathrm{~A}$ pril 2005 of guilt. In essence, the physical pains of abortion tend to last for a short period but the psychological pains sometimes last for a lifetime and could lead to other conditions such as serious ill-health and crime (particularly if infertility occurs and persists).

A ttitude to U nwanted Pregnancy, Induced A bortion and $U$ nwanted $C$ hildren

Participants regarded unwanted pregnancy, induced abortion and unwanted children as closely related. They believed that the result of unwanted pregnancy is either induced abortion or the birth of an unwanted child. In essence, many women who were confronted with the problem of unwanted pregnancies would have tried induced abortion. Some were said to have succeeded even when their health and lives were at risk. A substantial proportion lost their lives, suffered infertility or the loss of or damage to one or more internal organs such as the womb and bladder. Some of such women would experience delay in getting pregnant and frequent miscarriages. Majority of the Christian and Muslim participants had negative perception of induced abortion. H owever, the Christians felt that induced abortion is acceptable if it would save the family from shame. The Muslims regarded abortion as murder and wickedness. Some participants, including nurses, spoke against abortion that they suggested capital punishment for anyone found guilty. On the other hand, medical practitioners were generally more favourable and they felt that abortion is acceptable in cases involving rape, under-aged and over-aged women and when the woman has already given birth to too many children. Some participants supported abortion in cases where education of the young girl is likely to be disrupted or where the paternity of the pregnancy is in dispute.

It is interesting to note the significant divergence of opinions between the medical practitioners and nurses who are supposed to be 'partners in progress' as far as the health sector is concerned. Such divergence of opinion could be 


\section{A frican Journal of R eproductive $\mathrm{H}$ ealth}

due to differences in the process of training for the two groups of professionals, particularly the length of time and degree of exposition vis-àvis research, access to books, journals and new developments in the health sector especially in other parts of the world. It is important to note the views of the medical practitioners in relation to advocacy with regard to a review of the abortion law in $\mathrm{N}$ igeria. The likely sources of opposition such as the religious groups should be noted and engaged during advocacy for the reformation of the abortion law.

Those women who were confronted with unwanted pregnancies but could not procure abortion, probably because of their belief, lack of support from their partners and parents, ignorance of the means of procuring safe abortion, lack of financial support, and fear of the consequences of abortion were forced to give birth to unwanted children. The focus of respondents was mainly on the rights of such children. The children were said to be vulnerable to abuse (neglect and discrimination) especially those with doubtful paternity, who would be regarded as and called bastards. They could be denied their rights to education, proper upbringing, inheritance, etc.

Although the $\mathrm{N}$ igerian constitution does not classify any child as illegitimate, the practice of regarding some children as unwanted and without rights goes on unabated. This situation requires intervention to ensure that the rights of such children are protected.

Adoption and the adoption law are pertinent issues in this case. If they are firmly established in the society, unwanted children could be adopted and their rights thereby protected. However, considering the attitude of many of the participants to adoption, enacting an adoption law would require public enlightenment to enable the public to be favourably disposed to it. The attitude of people to certain issues as unwanted pregnancy, induced abortion and unwanted children is very crucial with regard to this particular study. Attitude may be deep-seated and very difficult to deal with. This situation would require the design and planning of various actions and public enlightenment programmes through formal and informal education with involvement of the various mass media.

\section{Conclusion}

The problem of unwanted pregnancy and induced abortion is one that affects all strata of the society. It is recognised even at the rural level in N igeria. U rgent and deliberate steps must be taken by the various levels of government through legislation and policy reform. There is need for a reform of the present provisions of the criminal and penal codes on termination of pregnancy in order to protect the physical and mental health and lives of women in N igeria in accordance with the development brought to the "English Abortion Law", O ffences A gainst the Person Act 1861, by the court decision in R. V. Bourne. ${ }^{17}$ The 1861 British Parliamentary $O$ ffences A gainst the Person Act is one of the sources of the "N igerian Abortion Law." While the $\mathrm{N}$ igerian law has not been reformed, the E nglish law has been amended in 1967 and 1990.

A qualitative research is necessary to understand the factors that prevent the translation of the high contraceptive awareness to usage with a view to addressing them. Policy can then be put in place to encourage contraceptive usage and reduce the incidence of unwanted pregnancy and consequently induced abortion. Policymakers need to address the issue of unwanted children and enact an acceptable adoption law to protect the rights of such children.

\section{Acknowledgements}

We wish to acknowledge the invaluable contributions of our consultants, supervisors, logistic personnel, note-takers and other field staff in the planning and conduct of this study. The John D. and Catherine T. M acA rthur Foundation 
(G rant N 0. 27895) supported the study. The findings and conclusions are those of the authors and do not necessarily represent the views of The John D. and Catherine T. M acA rthur Foundation.

\section{References}

1. A dewoleIF. Trends in postabortal mortality and morbidity in I badan, $\mathrm{N}$ igeria. Int I $\mathrm{G}$ ynaecol 0 bstet 1992; 38(2): 115- 118.

2. E muveyan EE and Agboghoroma OC. Trends in abortion related maternal mortality in Lagos, $N$ igeria. T rop 10 bstet G ynaecol 14(1): 39- 41.

3. World Health $\mathrm{O}$ rganisation. Unsafe A bortion: $G$ lobal and Regional Estimates of I ncidence of and Mortality D ue to Unsafe Abortion with a Listing of Available Country D ata. G eneva, World H ealth O rganisation, 1998 (WH O / RH T / M SM / 97.16).

4. Unuigbe $J A$, O ronsanye $A U$ and $O$ rhue $A E$. A bortion related morbidity and mortality in Benin City, N igeria. 1973-1985. Int J G ynaecol 0 bstet 26: 435-439.

5. O konofua $\mathrm{FE}, \mathrm{O}$ dimegwu $\mathrm{C}, \mathrm{A}$ jabor $\mathrm{H}$, et al. Assessing the prevalence and determinants of unwanted pregnancy and induced abortion in N igeria. Stud Fam Plann 1999; 30(1): 67-77.

6. H enshaw SK, Singh $S, O$ ye-A deniran BA, A dewoleI $F$, I were $N$ and CucaY P. Theincidence of induced abortion in $\mathrm{N}$ igeria. Int Fam Plann Persp 1998; 24(4): 156- 164.

7. A dewole IF, 0 ye-A deniran $B A$, I were $N$, O ladokun A, G badegesin A and Babarinsa Al.
Contraceptive usage among abortion seekers in N igeria. W A fr J M ed 2002; 21(2): 112-114.

8. Population Reference Bureau. World Population D ata Sheet, 2002.

9. O toide $\mathrm{O}, \mathrm{O}$ ronsanye $\mathrm{F}$ and $\mathrm{O}$ konofua $\mathrm{FE}$. Why $\mathrm{N}$ igerian adolescents seek abortion rather than contraception: evidence from focus group discussions. Int Fam Plann Persp 2001; 27(2): 7781.

10. Alan G uttmacher Institute. Sharing R esponsibility: W omen, Sodety and A bortion W orldwide. N ew York: The Alan G uttmacher Institute, 1999.

11. $\mathrm{H}$ of $\mathrm{C}$ and Richters A. Exploring the intersections between teenage pregnancy and gender violence: lessons from Z imbabwe. A fr J R eprod H ealth 1999; 3(1): 51-65.

12. Shearer SB. The value of focus group research for social action programs. Stud Fam Plann 1981; 12(12): 407-408.

13. Folsch-Lyon $E$ and Trost J F. Conducting focus group sessions. Stud Fam Plann 1981; 12(12): 443449.

14. O sagbemi MO and Adepetu AA. G ender differences in the reason for participation in spouse sharing among the 0 kun in N igeria. A fr J R eprod $H$ ealth 2001; 5(2): 36-55.

15. Wolf $B, K$ nodel J and Sittitrai W. Focus group and survey as complementary research methods: examples from a study of the consequences of family size in Thailand. R esearch R eports 1991; N 0 91-213.

16. K nodel $J$ and Pramultratana A. Focus group research as a means of demographic enquiries. R esearch R eports 1987; N 0. 87- 106. 